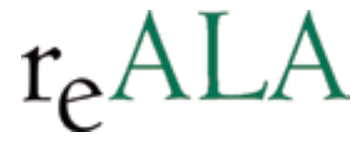

REALA, nos 315-316, enero-agosto 2011, ISSN: 1699-7476

\title{
El Estatuto Básico del Empleado Público: proyección e incidencia en la Administración Local, cumplidos cinco años desde su aprobación
}

\author{
Agustín Díez Quesada \\ Jefe de Área de Normativa Local Subdirección Ge- \\ neral de Administración Local Ministerio de Hacienda y Administraciones \\ Públicas \\ agustin.diez@seap.minhap.es \\ Recibido: 27 de junio de 2012 \\ Aceptado: 18 de julio de 2012
}

\section{Resumen}

Han pasado más de cinco años desde que el Estatuto Básico del Empleado Público fue aprobado por las Cortes Generales. Este artículo pretende ofrecer una visión global acerca de la incidencia que dicha norma posee en el régimen jurídico del empleo público local. Para ello, teniendo en cuenta la doctrina y la jurisprudencia recaída desde su aprobación, se analiza la problemática que plantea el encaje de dicha Ley dentro del sistema de fuentes aplicable a las dos clases de empleados públicos más numerosas -el personal funcionario y el personal laboral-; así como los marcos jurídicos para su desarrollo -con especial atención a los ámbitos reservados a las entidades locales-, y las disposiciones que en ese sentido el Estado y las Comunidades Autónomas han ido aprobando.

\section{Palabras clave}

Administración pública, administración local, Estatuto Básico del Empleado Público, empleo público local, función pública local, funcionarios con habilitación de carácter estatal.

\section{The Civil Servant Basic Statute: projection and impact on local government, after five years from approval}

\section{Abstract}

It has been over five years since the Civil Service Basic Statute was approved by Parliament. This article offers an overview about the impact that this law has in the legal status of local government employment. To do this, given the doctrine and jurisprudence relapse since its adoption, it analyzes the problems posed by that law lace of sources within the system applicable to both classes of public employees more numerous, as well as legal frameworks for development -with special attention to the areas reserved to local authorities-, and the provisions in this regard the State and the Autonomous Communities have been approved.

\section{Key words}

Public administration, local government, civil servant statute, local civil service, civil servants character enabled state. 


\section{INTRODUCCIÓN}

El pasado mes de mayo se cumplieron cinco años desde la aprobación' de la última gran reforma básica en materia de empleo público, la efectuada por la Ley 7/2007, de 12 de abril, del Estatuto Básico del Empleado Público (en adelante, EBEP); una norma que -según manifiesta su exposición de motivos- tiene como pretensión constituir “... un paso importante y necesario en un proceso de reforma, previsiblemente largo y complejo, que debe adaptar la articulación y la gestión del empleo público en España a las necesidades de nuestro tiempo...".

El periodo de tiempo transcurrido desde su aprobación, es más que razonable para hacer balance de la proyección y encaje que dicho instrumento ha tenido en el régimen jurídico del empleo público local, a la luz de las distintas interpretaciones jurisprudenciales y doctrinales que han ido recayendo a lo largo de este periodo.

Con ese objetivo, el presente trabajo pretende analizar en qué situación se halla a día de la fecha el marco jurídico diseñado por el EBEP para las dos clases de empleados públicos más numerosas en la Administración Local: el personal funcionario de carrera y el personal laboral; tomando para ello en consideración tanto su encaje dentro del sistema anterior, como los desarrollos que se han producido y los que se pudieran llegar a producir.

\section{EL MARCO JURÍDICO DEL EMPLEO PÚBLICO LOCAL EN EL ESTATUTO BÁSICO DEL EMPLEADO PÚBLICO}

El artículo 2 y la disposición final primera del Estatuto, incluyen de manera indubitada dentro de su ámbito de aplicación a todas las Entidades Locales, así como -si bien, con diferente intensidad- a las distintas entidades vinculadas o dependientes de aquéllas².

En ese sentido, la exposición de motivos hace alusión a las notas de heterogeneidad y pluralidad que caracterizan el empleo público local' , y ante ese hecho aboga por no configurar el régimen de la función pública sobre el modelo de la Administración General del Estado", apelando a que "cada Administración Pública debe poder configurar su propia política de personal", sin merma de la cohesión y la coordinación consiguiente.

Cabe preguntarse entonces, cuál es marco jurídico que establece el EBEP en materia de empleo público local. A continuación trataremos de aproximarnos a esta cuestión, abordando de modo separado el régimen jurídico del personal funcionario, del aplicable al personal laboral.

\section{a) El personal funcionario local}

En lo que respecta al personal funcionario, el artículo 1.1 del EBEP señala que el objeto del Estatuto es establecer, con carácter de legislación básica, "las bases del régimen estatutario de los funcionarios públicos incluidos en su ámbito de aplicación", pretendiendo de este modo dar cumplimiento -si bien, de modo parcial-, al mandato expresado en el artículo 103.3 de la Constitución española (en adelante, CE), mediante el empleo de los títulos competenciales enumerados en su disposición final primera.

Desde el punto de vista formal, con el Estatuto el legislador se ha desmarcado de la técnica seguida en otras materias, consistente en aprobar una regulación "completa", que incluya preceptos de carácter básico junto a otros únicamente de aplicación a la Administración General del Estado; técnica empleada por ejemplo, en la ley de patrimonio de las Administraciones Públicas o la de contratos del sector público. El EBEP es una norma íntegramente básica ${ }^{5}$, circunstancia que provoca -como ha señalado la doctrina ${ }^{6}-$, que el desarrollo de las bases estatales deba acometerse no sólo por las Comunidades Autónomas, sino también por el propio Estado7.

1 De conformidad con el apartado 1 de su disposición final cuarta, y sin perjuicio de las previsiones que dicha disposición efectúa para determinadas materias, el Estatuto entró en vigor en el plazo de un mes a partir de su publicación en el Boletín Oficial del Estado, es decir, el día 13 de mayo de 2007 -norma publicada en el BOE núm. 89, de 13 de abril de 2007-.

2 En ese sentido, vid. "Criterios para la aplicación del Estatuto Básico del Empleado Público en el ámbito de la Administración Local", suscritos conjuntamente por la Dirección General de la Función Pública y la Dirección General de Cooperación Local del Ministerio de Administraciones Públicas (Criterios generales de aplicación, apartado 1.1). También la jurisprudencia ha ido perfilando el ámbito de aplicación del EBEP. Es interesante la Sentencia del Tribunal Superior de Justicia de País Vasco (Sala de lo Social, Sección 1ª) de 23 junio 2009 (RJ AS|2009|2284), en la que -además de invocar la jurisprudencia relativa a la prohibición de la denominada "técnica del espigueo"-, perfila el régimen al que queda sujeto el personal de una Sociedad Mercantil con el 100\% de capital municipal (concretamente, Aguas de Vitoria, S. A.).

3 En ese sentido, la exposición de motivos del EBEP señala que "... la emergencia de las Administraciones autonómicas, que hoy cuentan prácticamente con la mitad de los empleados públicos del país, ha hecho aflorar sus propios problemas y necesidades de gestión de personal. Algo semejante puede decirse de las Entidades Locales, que presentan por lo demás hondas diferencias entre ellas, en las que el número de empleados ha experimentado también un importante crecimiento."

4 Señala la exposición de motivos del EBEP que “...cada Administración debe poder configurar su propia política de personal, sin merma de los necesarios elementos de cohesión y de los instrumentos de coordinación consiguientes. Por tanto, la densidad de la legislación básica en materia de función pública debe reducirse hoy en día, en comparación con épocas pasadas, teniendo en cuenta en todo caso las determinaciones de los Estatutos de Autonomía y la doctrina establecida por el Tribunal Constitucional."

5 Excepto en lo relativo a la legislación laboral, donde se emplea el título del artículo 149.1.7 CE.

6 V. Álvarez Rico, Manuel, González-Haba Guisado, Vicente Mª y Orduña Prada, Enrique, Administración y empleo público en España, CEMCI-Diputación Provincial de Granada, Granada, 2011 (pág. 362).

7 En ese sentido, V. AA.VV., Documentos para la reforma de la función pública. Xunta de Galicia. La Coruña, 2008 (pág. 33 ). 
Sin perjuicio de las especialidades existentes para determinados cuerpos o escalas ${ }^{8}$, el artículo 3.1 del EBEP ha configurado el sistema general de fuentes aplicable al personal funcionario de la Administración Local, señalando que éste "se rige por la legislación estatal que resulte de aplicación, de la que forma parte este Estatuto y por la legislación de las Comunidades Autónomas, con respeto a la autonomía local."

Vaya por delante, que el sistema de fuentes que diseña el artículo 3.1 del EBEP no es un sistema estático, ya que su alcance efectivo está condicionado por el ejercicio de desarrollo que efectúen -dentro de sus respectivos marcos competenciales-, los legisladores estatal y autonómico, y por el espacio que éstos reserven a las entidades que integran la Administración Local; circunstancia que entre otras cuestiones, y hasta tanto se produzca dicho desarrollo, provoca inseguridad jurídica en diversos aspectos. No obstante lo anterior, a continuación trataremos de determinar cuáles son los posibles límites del sistema de fuentes diseñado por el artículo 3.1.

En lo que se refiere a la legislación estatal, la literalidad del artículo 3 hace referencia a la "que resulte de aplicación, de la que forma parte este Estatuto”, pero ¿a qué legislación estatal alude? ¿Está toda la legislación básica en materia de función pública local contenida en el EBEP? Ambas cuestiones son relevantes no sólo para fijar el régimen jurídico de aplicación al personal funcionario local, sino también para establecer el punto de partida que debiera respetar la normativa de desarrollo.

Una interpretación gramatical del artículo 3.1 nos lleva a deducir que la legislación básica no va a estar conformada únicamente por el EBEP, ya que éste va "a formar parte" de la misma. Y es que efectivamente, en materia de función pública el EBEP no es la única norma básica vigente. También son básicas, entre otras, la Ley de Incompatibilidades del Personal al Servicio de las Administraciones Públicas (tal y como se deduce expresamente de la disposición final $3^{\text {a }}$ del propio EBEP), o la Ley de Prevención de Riesgos Laborales (como expresa su disposición adicional $3^{\mathrm{a}}$ ).

Por tanto, existen otras normas básicas además del EBEP, que van a ser de aplicación no solo a la Administración Local sino a conjunto de las Administraciones Públicas. Ahora bien ¿el legislador se refiere únicamente a este bloque, o va más allá y pretende aludir a la normativa integrada o que pudiera integrarse dentro de la legislación básica de régimen local?

En materia de función pública local, el Estado ha obtenido legitimación competencial proveniente de dos títulos diferentes, residenciados ambos en el artículo 149.1.18 ${ }^{\mathrm{a}}$ de la CE. De un lado, el relativo a la competencia exclusiva para establecer las bases del régimen estatutario de los funcionarios públicos, y de otro, el relativo a la competencia exclusiva para la aprobación de la legislación básica en materia de régimen local -incluida aquí, la función pública local-.

En lógica correspondencia con su carácter de legislación básica, el EBEP incluye en su ámbito de aplicación "a la Administración de las Comunidades Autónomas". Sin embargo, en contraposición con lo que sucede con el personal funcionario de las Entidades Locales, el EBEP no define cuál es el sistema de fuentes para el personal al servicio de las Comunidades Autónomas, a quienes también les será de aplicación la restante legislación básica del Estado en materia de función pública, además del EBEP.

Este razonamiento avala la interpretación de que el legislador, cuando en el artículo 3 del EBEP define el sistema de fuentes aplicable al personal funcionario de las Entidades Locales, con la referencia a "la legislación estatal que resulte de aplicación", pretende aludir a aquellos preceptos de función pública que se integran o pudieran integrarse en un futuro dentro del régimen jurídico básico local.

Refuerza esta hipótesis el hecho de que la disposición derogatoria del EBEP, haga referencia únicamente a determinados preceptos de la legislación básica de régimen local que colisionan con el EBEP -el artículo 92 y el Capítulo III del Título VII de la Ley Reguladora de Bases de Régimen Local (en adelante, LRBRL) y el Capítulo III del Título VII del Texto Refundido de las disposiciones legales vigentes en materia de Régimen Local-, sin aludir a las restantes disposiciones de carácter básico contenidas en la normativa de régimen local. Por ello, si la voluntad del legislador hubiera sido eliminar los preceptos de función pública local incorporados en el bloque normativo básico de régimen local, éstos hubieran sido derogados en bloque.

Asimismo, el Tribunal Constitucional, cuya jurisprudencia el legislador dice haber tenido cuenta en la redacción del EBEP -ya que así lo indica en la exposición motivos-, ha reafirmado la doble legitimación competencial del Estado entre otras en la ilustrativa STC 37/2002

8 Como por ejemplo, los funcionarios de los Cuerpos de Policía Local, o los de la Escala de funcionarios de Administración Local con habilitación de carácter nacional.

9 Sentencia del Tribunal Constitucional 37/2002, de 14 febrero (RTC|2002/37). 
“En materia de función pública al Estado le corresponde, en virtud de lo establecido en el art. 149.1.18 CE, la competencia exclusiva para establecer las bases del régimen estatutario de los funcionarios públicos, expresión que ha de entenderse referida, como ha tenido ocasión de declarar el Tribunal Constitucional, a los funcionarios de todas las Administraciones públicas, debiendo, por consiguiente, entenderse incluidos en dicho título competencial tanto los funcionarios de la Administración del Estado como los de las Administraciones de las Comunidades Autónomas y los de las Corporaciones Locales (SSTC 57/1982, de 27 de julio [RTC 1982, 57], F. 12; 25/1983, de 7 de abril [RTC 1983, 25], F. 4; 76/1983, de 5 de agosto [RTC 1983, 76], F. 44; 85/1985, de 10 de julio [RTC 1983, 85], F. 1; 235/1991, de 12 de diciembre [RTC 1991, 235], F. 2; 385/1993, de 23 de diciembre, F. 8).

Por su parte la Comunidad Autónoma de Cataluña ha asumido, en el marco de la legislación básica del Estado, competencia de desarrollo legislativo y ejecución en materia de régimen estatutario de sus funcionarios (art. 10.1 .1 EAC), título competencial que abarca a los funcionarios al servicio de la Comunidad Autónoma, y competencia exclusi$\mathrm{va}$, sin perjuicio de lo dispuesto en el art. $149.1 .18^{\circ} \mathrm{CE}$, en materia de régimen local (art. 9.8 EAC), título competencial de carácter globalizador en cuanto comprensivo de la totalidad de los aspectos que se refieren a la Administración local (STC 233/1999, de 16 de diciembre [RTC 1999, 233], F. 4), incluida, por tanto, la función pública local.

Resulta pues acorde con la jurisprudencia del TC, interpretar que el artículo 3 del EBEP ha optado por el mantener un sistema de fuentes que confiera cobertura a la "doble competencia" estatal en materia de función pública local y, como consecuencia, el mantenimiento en vigor de las disposiciones reguladoras del empleo público local integradas dentro del bloque normativo básico del régimen local -en todo aquello en lo que no se oponga al EBEP-, circunstancia que también ha reconocido la jurisdicción contencioso-administrativa ${ }^{10}$, así como nutrida parte de la doctrina ${ }^{11}$.

Por ello, de la aprobación del EBEP no puede colegirse prima facie una completa y total derogación de las disposiciones de función pública local contenidas en el bloque normativo básico de régimen local. Eso sí, la vigencia de estas últimas va a quedar condicionada -en aplicación de la letra g) de la disposición derogatoria única del EBEP-, a que no contradigan al Estatuto, obligando así al operador jurídico a una labor de exégesis ${ }^{12}$ que en muchas ocasiones no resulta todo lo pacífica que sería deseable.

En otro orden, parte de la doctrina ${ }^{13}$ considera que el artículo 3.1 del EBEP ha alterado el sistema de fuentes que regula el régimen jurídico de los funcionarios de Administración Local, en lo que se refiere al orden de aplicación y prelación de la legislación estatal. Así, mientras que el derogado artículo 92.1 de la LRBRL, establecía una prelación a favor de las normas de función pública residenciadas en la legislación básica de régimen local, sobre las de la legislación básica general ${ }^{14}$; el artículo 3.1 del EBEP, en la coordinación que efectúa entre ambos bloques normativos, entiende que las dudas o conflictos que puedan surgir se deben resolver a favor de la indicada en primer término, es decir a favor de la legislación básica general, puesto que el legislador ha pretendido convertir el Estatuto en una norma común de carácter universal para todas las Administraciones Públicas. No obstante lo anterior, los mismos autores admiten que esto no constituye una limitación para que desde la legislación básica de régimen local se pueda diseñar un autentico modelo de función pública local, siempre que éste respete las materias principales que derivan del EBEP ${ }^{15}$.

Pasando a continuación a analizar la capacidad de desarrollo de las Comunidades Autónomas, en primer término cabe recordar que el EBEP es, según indica su disposición final primera, una norma de carácter básico, dictada al amparo de los títulos competenciales reconocidos en el artículo 149.1, apartados $7^{\circ}, 13^{\circ}$ y $18^{\circ}$ de la CE.

10 Su vigencia se reconoce entre otras, expresamente en el F. J. $2^{\circ}$ de la Sentencia del Tribunal Superior de Justicia de Castilla y León, Burgos (Sala de lo Contencioso-Administrativo, Sección $2^{\mathrm{a}}$ ) núm. 56/2011 de 21 febrero (RJCA|2011|155) y, de modo indirecto, en el fundamento jurídico tercero de la Sentencia del Tribunal Superior de Justicia de Galicia (Sala de lo Contencioso-Administrativo, Sección 1a) núm. 22/2012 de 18 enero (RJ JUR|2012/37274).

11 En ese sentido, así se reconoce -aunque con críticas a la postura adoptada por el artículo 3 del EBEP- en: Toña Güenaga, Fernando (DIR) y otros, "Informe: Estatuto básico del empleado público y márgenes de configuración del legislador vasco para su desarrollo", Instituto Vasco de Administración Pública, Oñate, Guipúzcoa, 2007 (pág. 35 y 36); o Palomar Olmeda, Alberto (Coor.), El Estatuto Básico del Empleado Público y su incidencia en el ámbito local, CEMCI-Diputación Provincial de Granada, Granada, 2007 (pág. 65); también Cantero Martínez, Josefa, “Las situaciones administrativas en el Estatuto Básico del Empleado Público”, Revista de Administración Pública, núm. 176, Madrid, mayo-agosto (2008), págs. 161-197, reconoce la posibilidad de que en materia de situaciones administrativas “otras normas estatales pudieran regular o incidir en la materia" (pág. 165).

12 En ese sentido Vid. Ministerio de Administraciones Públicas, “Criterios para la aplicación del Estatuto Básico del Empleado Público en el ámbito de la Administración Local”, Dirección General de la Función Pública y Dirección General de Cooperación Local, Madrid, 2007.

13 En ese sentido Vid. Palomar Olmeda, Alberto (Coord.), El Estatuto Básico del Empleado Público y su incidencia en el ámbito local, CEMCI-Diputación Provincial de Granada, Granada, 2007, en especial págs. 65 a 67.

14 Dicho precepto disponía que: “Los funcionarios al servicio de la Administración Local se rigen, en lo no dispuesto por esta Ley, por la legislación del Estado y de las Comunidades Autónomas, en los términos previstos en el artículo 149.1.18 de la Constitución.”

15 Cabe advertir que el borrador del Anteproyecto de Ley para la racionalización y sostenibilidad de la Administración Local (versión 26.07.12.), otorga al artículo 92.1 de la LRBRL una redacción en términos muy similares a la actualmente derogada, lo que de aprobarse, restablecería el orden de prelación a favor de la LRBRL. 
No obstante, la aplicación general del EBEP se ve doblemente matizada en la propia norma. En primer término por la disposición adicional tercera, en lo que respecta a las Instituciones Forales de la Comunidad Foral Navarra y de la Comunidad Autónoma del País Vasco. Y en segundo lugar, por la disposición final segunda que prevé que el EBEP será de aplicación a todas las Comunidades Autónomas "respetando en todo caso las posiciones singulares en materia de sistema institucional y las competencias exclusivas y compartidas en materia de función pública y de autoorganización que les atribuyen los respectivos Estatutos de Autonomía, en el marco de la Constitución.

Esta última disposición, dirigida a todas las comunidades autónomas, parece querer salvaguardar la aplicabilidad del respectivo Estatuto de Autonomía frente al EBEP.

No se alcanza muy bien a determinar qué sentido tiene dicha disposición, dado que con carácter general la aprobación de una norma de carácter básico -como es el EBEP-, presupone la necesaria existencia del algún título competencial a favor del Estado -máxime desde la Sentencia del Tribunal Constitucional 61/1997 ${ }^{16}$-, por lo que la norma básica debería ser aplicada en todo caso; mientras que si por el contrario, el respectivo Estatuto de Autonomía prevé la competencia exclusiva de la comunidad autónoma, la norma estatal no sería de aplicación.

En ese sentido, cabe hacer una referencia al proceso de reforma estatutaria que se inició -con carácter previo a la entrada en vigor del EBEP- con la reforma del Estatuto de Autonomía de la Comunidad Valenciana, y que ha dado lugar a los estatutos que la doctrina ${ }^{17}$ ha calificado como "de segunda generación".

Dentro de este proceso, estarían incluidos -por orden cronológico de aprobación-, además de la citada reforma del Estatuto de Autonomía de la Comunidad Valenciana (L. 0.1/2006, de 10 de abril), las reformas de los Estatutos de Autonomía de Cataluña (L. O. 6/2006, de 19 de julio); de las Illes Balears (L. 0. 1/2007, de 28 de febrero); de Andalucía (L. O. 2/2007, de 19 de marzo); de Aragón (L. O. 5/2007, de 20 de abril); de Castilla y León (L. O. 14/2007, de 30 de noviembre) y, por último, de la Comunidad Autónoma de Extremadura (L. O. 1/2011, de 28 de enero).

Tanto en materia de función pública como en régimen local, las reformas emprendidas en los estatutos de segunda generación tienen en común -en mayor o menor medida-, una pretensión de ampliar los marcos competenciales de las respectivas comunidades autónomas; circunstancia que en algún supuesto, llegaba a plantear serias dudas acerca la capacidad del Estado para poder adoptar disposiciones básicas, tanto en razón de la materia como en razón del tipo de instrumentos que podía emplear para ello -dudas que en materia de empleo público, la propia disposición final segunda del EBEP contribuía a alimentar-.

En ese sentido, el Estatuto de Autonomía de Cataluña (en adelante, EAC) en materia de función pública prevé en su artículo 136, que corresponde a la Generalidad, con respeto del principio de autonomía local: "a) La competencia exclusiva sobre el régimen estatutario del personal al servicio de las Administraciones públicas catalanas (lo que engloba al personal al servicio de las Entidades Locales) y sobre la ordenación y la organización de la función pública, salvo lo dispuesto en la letra b)"; y “b) La competencia compartida para el desarrollo de los principios ordenadores del empleo público, sobre la adquisición y pérdida de la condición de funcionario, las situaciones administrativas y los derechos, deberes e incompatibilidades del personal al servicio de las Administraciones públicas."

Sin perjuicio de lo estipulado en su artículo 160 -que es el encargado de determinar las "competencias en régimen local"-, el citado artículo 136 del EAC debía ponerse necesariamente en relación con los artículos 110 y 111 del EAC, preceptos que venían a regular de modo general, respectivamente, el régimen de las competencias exclusivas y de las competencias compartidas de la Generalidad. En ese sentido, el artículo 111 del EAC, en aquellas materias atribuidas de forma compartida venía a establecer que “(...) corresponden a la Generalidad la potestad legislativa, la potestad reglamentaria y la función ejecutiva, en el marco de las bases que fije el Estado como principios o mínimo común normativo en normas con rango de ley, excepto en los supuestos que se determinen de acuerdo con la Constitución y el presente Estatuto (...)."

De una interpretación conjunta de las disposiciones mencionadas, podía llegar a colegirse no sólo una reducción del ámbito material en el que podía operar la normativa básica, sino también de los instrumentos en los que podía recogerse ésta.

La Sentencia del Tribunal Constitucional 31/2010, de 28 de junio ${ }^{18}$, ha venido a clarificar en cierto modo, la capacidad del Estado tanto en las cuestiones relativas al ámbito material en el que podía desplegarse la competencia

16 Sentencia del Tribunal Constitucional 61/1997, de 20 de marzo.

17 Álvarez Conde, Enrique, Reforma Constitucional y Reformas Estatutarias, Ed. lustel, Madrid, 2007. (pág. 505 y ss.).

18 Sentencia del Tribunal Constitucional 31/2010, de 28 de junio de 2010. Recurso de inconstitucionalidad 8045-2006. Interpuesto por noventa y nueve Diputados del Grupo Parlamentario Popular del Congreso en relación con diversos preceptos de la Ley Orgánica 6/2006, de 19 de julio, de reforma del Estatuto de Autonomía de Cataluña (publicada en el Boletín Oficial del Estado núm. 172, de 16 de julio de 2010 y posteriores correcciones de errores, publicadas en los Boletines Oficiales del Estado núm. 192 de 9 de agosto de 2010 y núm. 246 , de 11 de octubre de 2010, respectivamente) (RTC|2010|31). 
básica estatal en función pública -y por ende, también en la relación a la función pública local-, así como en relación a los instrumentos que éste puede emplear para definir ese "mínimo común denominador".

Así, en lo que respecta al plano material en relación con el título competencial estatal relativo a las "bases del régimen estatutario de los funcionarios públicos" -contemplado en el artículo $148.1 .18^{\circ}$ CE-, el Tribunal Constitucional, invocando expresamente la jurisprudencia contenida en la STC 37/2002, de 14 de febrero, afirma que:

“(... ) el art. 136 b) EAC, al formalizar la competencia autonómica como compartida, presupone la plena virtualidad de la competencia normativa básica del Estado en la materia (art. 149.1.18 CE); sin que la omisión en la relación no exhaustiva que efectúa de algún aspecto esencial del régimen estatutario de los funcionarios públicos, como son la carrera administrativa y el régimen disciplinario, limite en el precepto enjuiciado la plena efectividad de la competencia estatal, pues obvio es que la carrera administrativa puede ser incluida, como ocurre con el régimen retributivo (que tampoco se cita en el precepto estatutario impugnado), entre los "derechos" de los funcionarios, mientras que el régimen disciplinario guarda relación con los "deberes" de los mismos, derechos y deberes que, efectivamente, están incluidos en la controvertida letra b) (...)." (FJ. 82 ${ }^{\circ}$.

También, en lo que se refiere a la competencia básica estatal en materia de régimen local -igualmente radicada en el 149.1.18 CE-, el Tribunal Constitucional remarca que el artículo 160 del EAC, al reconocer competencias a favor de la Generalidad de Cataluña,

"(...) en "exclusividad", lo hace de manera impropia y no impide que sobre dichas competencias autonómicas puedan operar plenamente las bases estatales, específicamente las del art. 149.1.18 CE (...)." $\left(\right.$ FJ. $\left.100^{\circ}\right)$.

Por ello, desde el punto de vista material, el Tribunal Constitucional ha proclamado la integridad de los dos títulos competenciales a través de los que el Estado puede llegar a adoptar disposiciones básicas en materia de función pública local ${ }^{19}$.

En lo que se refiere al plano instrumental, el Tribunal Constitucional ha venido a declarar inconstitucional y nulo el inciso "como principios o mínimo común normativo en normas con rango de ley, excepto en los supuestos que se determinen de acuerdo con la Constitución y el presente Estatuto"20 del anteriormente analizado artículo 111 del EAC, fundamentando su decisión en que dicho precepto:

“(...), no se atiene estrictamente al concepto constitucional de las bases estatales, toda vez que las reduce a los "principios o mínimo común normativo" fijados por el Estado "en normas con rango de ley", cuando es lo cierto que, conforme a nuestra jurisprudencia, siendo aquél el contenido que mejor se acomoda a la función estructural y homogeneizadora de las bases y ésta la forma normativa que, por razones de estabilidad y certeza, le resulta más adecuada (por todas, STC 69/1988, de 19 de abril), no lo es menos que también es posible predicar el carácter básico de normas reglamentarias y de actos de ejecución del Estado (STC 235/1999, de 16 de diciembre), y son factibles en las bases un alcance diferente en función del subsector de la materia sobre la que se proyecten e incluso sobre el territorio (SSTC 50/1990, de 6 de abril y 147/1991, de 4 de julio, respectivamente)"

Lo que lleva al Tribunal Constitucional a determinar que,

"Si las bases son "principios" o "normación mínima" no es asunto a dilucidar en un Estatuto, sino sólo en la Constitución, vale decir: en la doctrina de este Tribunal que la interpreta. Ello es así, ante todo, por razones de concepto. Pero, además, por razones de orden estructural y práctico. De un lado, porque el concepto, el contenido y el alcance de las bases no pueden ser, como regla general, distintos para cada Comunidad Autónoma, pues en otro caso el Estado tendría que dictar uno u otro tipo de bases en función de lo dispuesto en cada Estatuto de Autonomía. De otro, porque, siendo mudables las bases (STC 1/2003, de 16 de enero), también lo es, en correspondencia inevitable, el ámbito disponible por la legislación de desarrollo, de manera que la rigidez procedimental de un Estatuto lo convierte en norma inapropiada para determinar con detalle el alcance de las potestades inherentes a esa legislación." (FJ. 60)

19 Por su interés, Vid. AAVV, Especial Sentencia 31/2010 del Tribunal Constitucional sobre el Estatuto de Autonomía de Cataluña de 2006, Revista Catalana de Derecho Público, EAPC-Generalidad de Cataluña, Barcelona, diciembre 2010, en especial, págs. $215-248$.

20 AA.VV., Especial Sentencia 31/2010 del Tribunal Constitucional sobre el Estatuto de Autonomía de Cataluña de 2006, Revista Catalana de Derecho Público, EAPC-Generalidad de Cataluña, Barcelona, diciembre 2010. 
En suma, la STC 31/2010 -aunque se refiere en exclusiva al EAC-, ha venido a despejar una parte importante de las dudas que originaban ${ }^{21}$ algunos preceptos de determinados estatutos de autonomía de segunda generación, acerca de la aplicabilidad de las bases estatales, su capacidad para aprobarlas en determinadas materias, y los instrumentos que las podían albergar.

Enumeradas las líneas maestras que a día de la fecha disponen la distribución competencial entre el Estado y las comunidades autónomas en materia de función pública local; pasamos a continuación a analizar los perfiles que delimitan la "autonomía local" en dicha materia.

El respeto al principio de "autonomía local" se invoca expresamente en el propio artículo 3 del Estatuto, en alusión a sus normas de desarrollo. En ese sentido, el EBEP no constituye una innovación, ya que el principio de autonomía local -proclamado tanto en el artículo 137 de la CE como en el artículo 6 de la Carta Europea de Autonomía Local- tenía sus líneas maestras ya definidas en la LRBRL, sin perjuicio de sus diversas manifestaciones en las distintas esferas del ordenamiento jurídico.

Para determinar los posibles contornos de la autonomía local en la materia de función pública, es preciso hacer referencia en primer término a la reserva de ley exigida para la regulación del "estatuto de los funcionarios públicos". Este requerimiento está contenido en el artículo 103.3 de la CE, y su alcance ha sido determinado por la jurisprudencia del Tribunal Constitucional, que ha fijado de una parte qué materias componen el referido "estatuto de los funcionarios públicos", y de otra qué alcance debe tener la regulación contenida en norma con rango de ley.

En lo que respecta a las materias integradas dentro del "estatuto de los funcionarios públicos", la ya invocada Sentencia del Tribunal Constitucional 37/2002 22 , haciéndose eco de una larga línea jurisprudencial (ya que reproduce los razonamientos expresados tanto en las STC 99/1987, de 11 de junio, como en la STC 235/2000, de 5 de octubre) señala que

\begin{abstract}
"En cuanto al alcance del enunciado constitucional "estatuto de los funcionarios públicos", el Tribunal Constitucional ha declarado que se trata de una expresión cuyos contornos no pueden definirse en abstracto y "a priori", pero en la que ha de entenderse comprendida, en principio, la normación relativa a la adquisición y pérdida de la condición de funcionario, a las condiciones de promoción de la carrera administrativa y a las situaciones que en ésta puedan darse, a los derechos y deberes y responsabilidades de los funcionarios y a su régimen disciplinario, así como a la creación e integración, en su caso, de cuerpos y escalas funcionariales y al modo de provisión de puestos de trabajo al servicio de las Administraciones públicas, pues habiendo optado la Constitución por un régimen estatutario, con carácter general, para los servidores públicos (arts. 103.3 y 149.1.18 CE) habrá de ser la Ley la que determine en qué casos y con qué condiciones puedan reconocerse otras posibles vías de acceso al servicio de la Administración pública." (FJ. $\left.5^{\circ}\right)$.
\end{abstract}

En ese sentido, el EBEP desarrolla directamente el mandato constitucional previsto en su artículo 103.3 23 , pero lo hace con carácter básico, sin llegar a satisfacer completamente el mandato constitucional en toda su extensión. Por ello, en la propia exposición de motivos $^{24}$ se hace referencia al necesario desarrollo legislativo del EBEP por parte del legislador estatal y autonómico -apelando expresamente al ámbito de sus competencias y al respeto a la autonomía organizativa de las Entidades Locales-, necesidad y exigencia que, dentro del articulado, y de un modo general, proclama el artículo 6.

Junto al genérico artículo 6 del EBEP, otros preceptos del Estatuto, en la regulación particular de las diversas materias que componen el estatuto del funcionario público -en correspondencia con la jurisprudencia del Tribunal Constitucional-, hacen referencia a las "leyes de desarrollo" o efectúan reservas a favor de normas con rango de ley.

De ese modo, el EBEP requiere expresamente a las leyes de desarrollo, entre otras cuestiones, para la definición de las funciones que correspondan en exclusiva a los funcionarios públicos -art. 9.2-; para la regulación de la carrera profesional - art. 16.3, 17 y 18- y en íntima conexión con ésta, para definir la estructura y cuantía de

21 En ese sentido vid. Serrano Pascual, Antonio, El Estatuto Básico del Empleado Público y las Entidades Locales: valoración crítica, Revista Estudios QDL, Fundación Democracia y Gobierno Local, núm. 15, Barcelona, octubre de 2007.

22 Sentencia del Tribunal Constitucional (Pleno), núm. 37/2002 de 14 febrero (RTC|2002/37).

23 Como expresamente así determina el artículo 1.1 del EBEP.

24 "En desarrollo de este Estatuto Básico, el legislador estatal y el de las Comunidades Autónomas, en el ámbito de sus respectivas competencias, habrán de aprobar o modificar las leyes de función pública de sus Administraciones, así como las normas aplicables a la Administración local, respetando en este último caso la autonomía organizativa de las Entidades Locales. Dichas leyes podrán ser, asimismo, generales o referirse a sectores específicos de la función pública que lo requieran." 
las retribuciones complementarias -artículo 24-; para la definición de los sistemas de estructuración del empleo público, así como para desarrollar los sistemas de provisión de puestos previstos en el EBEP -artículos 73, 78.3 79 y 80-; para la regulación de otras situaciones administrativas y para el desarrollo de las previstas -artículo 85.2 y siguientes-; o, por último para desarrollar el régimen disciplinario -artículos 93.1 y 95.4-. Asimismo, materias como la exención del requisito de la nacionalidad para el acceso a la función pública -artículo 57.5- o la creación, modificación y supresión de cuerpos y escalas -artículo 75.2-, quedan reservadas a norma con rango de Ley.

Ahora bien, ¿qué alcance debe tener la regulación que se efectúe por la ley? El Tribunal Constitucional, en la Sentencia $37 / 2002^{25}$ señala que,

"las normas que disciplinen estos ámbitos serán, en el concepto constitucional, ordenadoras del Estatuto de los funcionarios públicos" y dicha normación, en virtud de la reserva constitucional del art. 103.3 CE, "habrá de ser dispuesta por el legislador en términos tales que, de conformidad con lo antes observado, sea reconocible en la Ley misma una determinación material suficiente de los ámbitos incluidos en el estatuto funcionarial, descartándose, de este modo, todo apoderamiento explícito o implícito a la potestad reglamentaria para sustituir a la norma de Ley en la labor que la Constitución le encomienda" [STC 99/1987, de 11 de junio, F. 3 C); doctrina que reitera la STC 235/2000, de 5 de octubre (RTC 2000, 235), F. 5]." (FJ. $\left.5^{\circ}\right)$.

No obstante lo anterior, el TC matiza los límites de la reserva legal, precisando en qué medida el reglamento puede colaborar con ésta. A tal fin, señala que

"(... ) el estatuto de los funcionarios públicos, en virtud de la reserva de Ley "ex" art. 103.3 CE, queda sustraído a la formación reglamentaria, "mas no en el sentido de que las disposiciones del Gobierno no puedan, cuando así lo requiera la Ley, colaborar con ésta para complementar o particularizar, en aspectos instrumentales y con la debida sujeción, la ordenación legal de la materia reservada, pues esta colaboración que, en términos de política legislativa habrá de resultar pertinente en muchos casos, no será contradictoria con el dictado de la Constitución cuando la remisión al reglamento lo sea, estrictamente, para desarrollar y complementar una previa determinación legislativa". Esto es, "en esta materia habrá de ser sólo la Ley la fuente introductora de las normas reclamadas por la Constitución, con la consecuencia de que la potestad reglamentaria no podrá desplegar aquí innovando o sustituyendo a la disciplina legislativa, no siéndole tampoco posible al legislador disponer de la reserva misma a través de remisiones incondicionadas o carentes de límites". De modo que, como el Tribunal Constitucional tiene declarado en relación a otros ámbitos materiales reservados por la Constitución a la regulación por Ley, no es imposible en esta materia una intervención auxiliar o complementaria del reglamento, siempre que, como ya se señalara en la STC 83/1984, de 24 de julio (RTC 1984, 83) (F. 4), "esas remisiones sean tales que restrinjan efectivamente, el ejercicio de esa potestad (reglamentaria) a un complemento de la regulación legal, que sea indispensable por motivos técnicos o para optimizar el cumplimiento de las finalidades propuestas por la Constitución o por la propia Ley, de modo que no se llegue a una total abdicación por parte del legislador de su facultad para establecer reglas limitativas, transfiriendo esa facultad al titular de la potestad reglamentaria, sin fijar ni siquiera cuáles son los fines u objetivos que la reglamentación ha de perseguir" [STC 99/1987, de 11 de junio, F. 3 a)]. (FJ. $5^{\circ}$ ).

En ese sentido, el EBEP en determinadas cuestiones, como muestra de la posible intervención complementaria del reglamento, legitima a las “Administraciones Públicas” para llevar a cabo su regulación o ejecución -aunque no en términos absolutos-. Entre éstas figuran por ejemplo, determinados extremos de la carrera administrativa ${ }^{26}$; régimen retributivo ${ }^{27}$; jornada, permisos y vacaciones ${ }^{28}$; selección; planificación u ordenación.

Llegados a este punto, cabe preguntarse entonces qué capacidad posee la Administración Local para intervenir en materia de función pública.

Con anterioridad a la entrada en vigor del EBEP, la capacidad que las Entidades Locales tenían para "configurar su propia política de personal”, a grandes rasgos se circunscribía al ejercicio de las potestades reglamentaria y

25 Sentencia del Tribunal Constitucional (Pleno), núm. 37/2002 de 14 febrero (RTC|2002/37).

26 Entre ellas: la promoción la actualización y perfeccionamiento de la cualificación profesional de sus funcionarios de carrera (art. 16.2), adopción de medidas que incentiven la promoción interna y progresión en la carrera profesional (art. 18.4) y establecimiento y regulación de los sistemas de evaluación de desempeño (art. 20).

27 Retribuciones de los funcionarios en prácticas (art. 26).

28 Establecimiento de jornadas (art. 47) y determinación de supuestos de concesión de permisos (art. 48). 
de autoorganización, así como de programación o planificación, previstas en las letras a) y c) del artículo 4.1 de la LRBRL. Ello les permitía, siempre de conformidad con las disposiciones básicas estatales -algunas integradas dentro del bloque normativo básico de régimen local-, y en su caso autonómicas, de una parte planificar, seleccionar y gestionar sus recursos humanos, y de otra, ejercer su potestad reglamentaria en materias como tipos de jornada y horarios; apertura y cierre de departamentos; disfrute de vacaciones, permisos, licencias; confección de nóminas; o reglamentación del registro de personal.

En la actualidad, el EBEP plantea que cada Administración Pública pueda configurar su propia política de personal, y a tal efecto contrae -de un modo muy notable-, "la densidad de la legislación básica en materia de función pública"29; quedando reducida, en aspectos esenciales del estatuto del funcionario público, a principios, fundamentos, pautas, o normas muy generales.

Dejando al margen la cuestión relativa a su entrada en vigor -que se estudiará en el apartado siguiente-, numerosos autore ${ }^{30}$ coinciden en señalar que buena parte del Estatuto requiere del "complemento indispensable del legislador, estatal o autonómico, de desarrollo". Y es que efectivamente, incluso la propia la disposición final cuarta del EBEP, en su apartado segundo condiciona expresamente la entrada en vigor de una parte significativa ${ }^{31}$ de los preceptos del Estatuto -los que regulan cuestiones como la carrera administrativa, promoción interna y evaluación del desempeño; derechos retributivos; o provisión de puestos de trabajo y movilidad- hasta "la aprobación de las Leyes de Función Pública de las Administraciones Públicas que se dicten en desarrollo" del EBEP; lo que, entre otras consecuencias, pospone también la definición concreta de un posible nuevo modelo y los márgenes de actuación de los que van a disponer las Entidades Locales.

Sin perjuicio de que algunos preceptos del EBEP en materia de función pública posean eficacia directa ${ }^{32}$ sin necesidad de complemento normativo alguno ${ }^{33}$, lo cierto es que una parte muy relevante de su contenido requiere de la legislación de desarrollo, y en el ámbito local será ésta quien a la postre concrete el modelo de empleo público, así como los espacios de intervención y desarrollo reglamentario que quedan reservados a las entidades que integran la Administración Local.

No obstante lo anterior, algunos autores 34 -aunque haciendo referencia al Ayuntamiento de Madrid ${ }^{35}-$, han llegado a apelar a la posibilidad de desarrollo directo del EBEP de modo general, aún en ausencia de regulación de desarrollo, todo ello "en ejercicio de su poder normativo de autoorganización" 36 ; aunque reconocen que una futura ley podría derogar "selectiva y parcialmente la regulación municipal”, circunstancia que a su juicio, no pondría en cuestión "la existencia del poder normativo municipal, sino la vigencia en el tiempo de la Ordenanza municipal de personal o empleo público".

A nivel jurisdiccional, la Sentencia del Tribunal Superior de Justicia de Asturias 1055/09, de 10 de junio, avala indubitadamente la primera interpretación al señalar -en relación con la carrera profesional- del Estatuto que:

“(... ) su vocación de norma básica le ha llevado a diferir en el tiempo la concreción del modelo, lo que habrán de hacer las CCAA, o el propio Estado en relación a sus empleado, a través del ejercicio de su potestad legislativa (...)

No se puede por tanto hurtar a los representantes de la soberanía su potestad de efectuar ese desarroIlo, no siendo en consecuencia la vía convencional, y ni siquiera la reglamentaria sin ese soporte legal previo, instrumentos ni cauces adecuados para establecer una carrera profesional, ni siquiera de forma provisional (...)" (F. J. $4^{\circ}$ ).

29 Como reconoce expresamente la propia exposición de motivos del EBEP.

30 Entre estos, Martín Rebollo, Luís., El Estatuto Básico del Empleado Público: un Godot que no ha llegado, Revista de Administración Pública, núm. 174, Madrid, septiembre-diciembre 2007 (pág. 130) y Serrano Pascual, Antonio., El estatuto básico del empleado público y las Entidades Locales: valoración crítica, Estudios QDL, 15. Octubre 2007 (pág. 98).

31 También es significativa desde el punto de vista cuantitativo, ya que los artículos 16 a 30 (excepto el 25.2 ) y 78 a 84 ya suponen prácticamente un 25 por 100 del articulado del EBEP.

32 Podrían incluirse aquí -aunque con matices-, por ejemplo, negociación colectiva; jornada de trabajo, permisos y vacaciones; adquisición y pérdida de la condición de funcionario; situaciones administrativas; y parte del régimen disciplinario.

33 En ese sentido en Díez Quesada, Agustín y González-Haba Guisada, Vicente, "El Estatuto Básico del Empleado Público y sus posibilidades renovadoras del empleo público local”, en Almonacid Lamelas, Víctor (Coor.), “Estudios sobre modernización de la Administración Local: Teoría y Práctica”, Libro II, Capítulo II, La Ley-El Consultor de los Ayuntamientos, Madrid, 2009, se apuntan aquellos preceptos del EBEP que pueden ser de directa aplicación para las Entidades Locales.

34 AA.VV., Estudio del Estatuto Básico del Empleado Público, Ayuntamiento de Madrid, Editorial Aranzadi, Navarra, 2008 (págs. 13-24).

35 Invocando expresamente el artículo 20 de la Ley 22/2006, de 4 de julio, de Capitalidad y Régimen Especial de Madrid (nota anterior, pág. 15).

36 Dichos autores afirman que "En ausencia de regulación autonómica, el Ayuntamiento puede ejercer directamente su poder normativo y de autoorganización para desarrollar el EBEP” (pág. 16). 
En esa línea, la reciente Sentencia del Tribunal Superior de Justicia de Castilla y León ${ }^{37}$ 56/2011, de 21 febrero, señala en relación a las administraciones locales que:

“No puede perderse de vista además que, conforme a lo dispuesto en el apartado 2 de la Disposición Final Cuarta del Estatuto Básico, no obstante haber entrado en vigor el 13 de mayo de 2007, los preceptos contenidos en los capítulos II y III de su Título III, a salvo el art. 25.2, así como en el capítulo III del Título V solo producirán efectos "a partir de la entrada en vigor de las Leyes de Función Pública Tribunal Superior de Justicia de Castilla y León, Burgos (Sala de lo Contencioso-Administrativo, Sección $2^{a}$ ). Sentencia núm. 56/2011 de 21 febrero que se dicten en desarrollo de este Estatuto", desarrollo legal que no ha tenido aún lugar, siendo así que, en el ínterin, y a tenor del apartado 3 de la citada Disposición Final Cuarta, "se mantendrán en vigor en cada Administración Pública las normas vigentes sobre ordenación, planificación y gestión de recursos humanos en tanto no se opongan a lo establecido en este estatuto". (FJ. $2^{\circ}$ )

Lo que ha llevado a la Sala a considerar, en relación con el principio de autonomía municipal -invocando aquí expresamente el criterio del Tribunal Supremo (formulado en STS de 9 de Septiembre del 2010 ${ }^{38}$ )-, que:

"según jurisprudencia reiterada de esta Sala, que la autonomía municipal art. 140 CE no permite a las Corporaciones locales invadir ámbitos no atribuidos a su competencia, por incidir en intereses de orden general atribuidos normativamente al Estado, aún concurrentes con los de la propia Entidad local y con sujeción al Decreto 315/64, a las leyes 30/84 y 7/85 y al Real Decreto Legislativo 781/86, así como a la legislación complementaria."

En suma, la notable reducción de la densidad de la legislación básica en materia de función pública, consecuencia de la aprobación del EBEP, sí ha supuesto a priori un potencial aumento de la capacidad de las comunidades autónomas "para configurar sus propias políticas de personal”, ya que en lógica correspondencia con la reducción de la legislación básica, se ha ampliado el margen de desarrollo que posee el legislador autonómico.

Ahora bien, en líneas generales, en el ámbito local el Estatuto no ha supuesto por sí mismo una alteración de la capacidad de las Entidades Locales para configurar su política de personal, ya que ésta, en una parte muy importante exige del complemento del legislador; cuestión que -al menos en principio- el artículo 3 del EBEP no atribuye única y exclusivamente al legislador autonómico, ya que -como se ha expresado- dicho precepto también legitima al Estado para la utilización de sus títulos competenciales.

\section{b) El personal laboral local}

El personal laboral constituye en el ámbito local el colectivo de empleados públicos más numeroso. Antes de la aprobación del EBEP, su marco jurídico venía establecido esencialmente por lo dispuesto en el Estatuto de los Trabajadores y, en su caso, en el respectivo convenio colectivo, aunque también existía un escaso número de preceptos específicos para aquéllos que prestaban sus servicios en la Administración Pública (contenidos esencialmente en la Ley de medidas de reforma de la Función Pública), a los que habría que añadir una serie de normas particulares para el régimen local.

EI EBEP ha constituido una novedad en el ordenamiento jurídico, al regular en sus aspectos más esenciales el sistema de empleo público en su conjunto, incluyendo dentro de él, normas que configuran la relación del personal laboral; estipulando en su artículo 7 que el personal laboral se rige "además de por la legislación laboral y por las demás normas convencionalmente aplicables, por los preceptos de este Estatuto que así lo dispongan."

En esta materia, el EBEP se asienta principalmente sobre el título competencial ${ }^{39}$ presente en el artículo 149.1.7 $7^{\mathrm{C}} \mathrm{C}$, que reserva al Estado la competencia exclusiva sobre legislación laboral, título que en principio excluye de la misma a legislación autonómica ${ }^{40}$. Por ello, en esta materia, a diferencia de lo que sucede con el estatuto de los funcionarios públicos, no existe concurrencia competencial, ni entre legislación estatal funcionarial y legislación estatal de régimen local; ni entre el legislador estatal y el autonómico.

En lo que respecta a la relación del EBEP con el derecho laboral, la doctrina ${ }^{41}$ considera que el Estatuto tiene para el personal laboral al servicio de las Administraciones Públicas carácter preeminente sobre cualquier otra

37 Sentencia del Tribunal Superior de Justicia de Castilla y León, Burgos (Sala de lo Contencioso-Administrativo, Sección $2^{\text {a }}$ ) núm. 56/2011 de 21 febrero (RJCA|2011|155).

38 Sentencia del Tribunal Supremo (Sala de lo Contencioso-Administrativo, Sección 7 a) de 16 noviembre 1994 (RJ|1995l555).

39 Así se anuncia en la exposición de motivos y se reconoce en la disposición final primera.

40 Así lo reconocen también AAVV, Documentos para la reforma de la función pública. Junta de Galicia. La Coruña, 2008 (pág. 335 ).

41 V. Palomar Olmeda, Alberto (Coord.), El Estatuto Básico del Empleado Público y su incidencia en el ámbito local, CEMCI-Diputación Provincial de Granada, Granada, 2007 (pág. 67). 
norma procedente de las Administraciones Públicas, completándose dicha regulación mediante su integración con la normativa laboral.

No obstante lo anterior, tal integración no ha sido en algunas cuestiones, todo lo pacífica que cabría desear. Así, en materia de jornada, permisos y vacaciones, el alcance y efectos del artículo 51 en relación con los restantes artículos del capítulo V del título III, ha sido objeto de interpretación dispar por las Salas de lo Social de distintos Tribunales Superiores de Justicia ${ }^{42}$, hasta que el Tribunal Supremo ${ }^{43}$ sentó una línea jurisprudencial que vino a determinar que los artículos 47 a 50 están dirigidos esencialmente a quienes ostentan la condición de funcionarios públicos.

Sin perjuicio de lo indicado, en el desarrollo de lo que disponen tanto el EBEP como el derecho laboral, tiene reservado un importantísimo papel la negociación colectiva ${ }^{44}$, puesto que materias tan trascendentales como la carrera profesional y la promoción del personal laboral (artículo 19.2), su régimen retributivo (artículo 27), las situaciones (artículo 92) o el régimen disciplinario (artículo 93 y siguientes), quedan dentro del nuevo marco legal establecido por el Estatuto y remitidas expresamente a lo que se recoja en los respectivos convenios.

Asimismo, en materia de selección el EBEP faculta a que los convenios puedan recoger "formas de colaboración" con las Organizaciones Sindicales en el desarrollo de los procesos selectivos (artículo 61.7), colaboración que deberá respetar, entre otros, los límites que establece el artículo 60 para los órganos de selección. Y en materia de provisión de puestos y movilidad, el artículo 83 faculta a la negociación, pero -novedosamente en esta materiahace una remisión en el supuesto de ausencia de negociación, a la normativa aplicable en esta materia para los funcionarios de carrera.

Por ello, la importancia del EBEP radica no sólo en la regulación conjunta de algunos aspectos para todos los empleados públicos, sino también en el amplio margen de desarrollo que en la configuración de las relaciones laborales ha otorgado a las Entidades Locales a través de los cauces de negociación colectiva; todo ello, sin perjuicio de las excepciones y limitaciones que posee la negociación, así como de su posible suspensión o modificación por causa grave de interés público, derivada de una alteración sustancial de las circunstancias económicas, tal y como contempla expresamente la nueva redacción otorgada al artículo 32 del EBEP.

\section{VIGENCIA Y DESARROLLO LEGISLATIVO DEL ESTATUTO BÁSICO DEL EMPLEADO PÚBLICO DESDE LA PERSPECTIVA LOCAL}

\section{a) Entrada en vigor y desarrollo}

Vaya por delante que la técnica seguida para regular la entrada en vigor del EBEP, ha provocado que uno de los mayores problemas que éste plantea, sea el de su encaje dentro del bloque normativo precedente. En ese sentido, su disposición final cuarta establece que con carácter general, el Estatuto entrará en vigor en el plazo de un mes a partir de su publicación; salvo determinados artículos -a los que se ha hecho mención en el apartado anterior del presente trabajo-, que entrarán en vigor una vez se aprueben las leyes de función pública de desarrollo.

Así pues, de entrada cabe distinguir dos tipos de preceptos: los que han entrado en vigor y los que no lo harán hasta que se aprueben las leyes de función pública de desarrollo. Respecto a los primeros, una buena parte de

42 EI TSJ de Castilla y León en diversas sentencias consideró que los convenios colectivos eran de aplicación preferente a lo establecido por el EBEP. Por el contrario, el TSJ de Valencia o el del País Vasco entendían que lo establecido en el EBEP, era de aplicación preferente a lo regulado en el respectivo convenio. Es también destacable la crítica que el Tribunal Superior de Justicia de Canarias (Sala de lo Social, Sección $1^{a}$ ), efectúa en su Sentencia núm. $1075 / 2009$ de 28 diciembre (RJ JUR|2010|137781), a “(...) la muy defectuosa técnica legislativa de la nueva ley $7 / 07$ (el EBEP) que nace con vocación de generalidad para regular las relaciones jurídicas de todos los empleados públicos, pero que su deficiente e inconexa técnica hace que se produzcan contradicciones, por solapamiento normativo con otros regímenes, tales como el laboral ordinario (caso de autos) o el personal estatutario (...)" (FJ. Segundo).

43 Valga por todas ellas, por su carácter ilustrativo, la Sentencia del Tribunal Supremo (Sala de lo Social, Sección $1^{\text {a) }}$ de 1 febrero 2011 (RJ 2011|2581), en la que literalmente señala:

“La cuestión planteada ha sido ya unificada por esta Sala en sus sentencias, entre otras, de 7 de diciembre de 2010 , (dos, recaídas en los RCUD. 4318 (JUR 2011, 29515) y 4415 de 2009 (JUR 2011, 29517)), 9 de diciembre de 2010 (dos, recaídas en el RCUD 4178/09 (JUR 2011, 39420 ) y en el 4397/09 (JUR 2011, 29543)), que han estimado más correcta la doctrina mantenida por la sentencia de contraste, solución que debe mantenerse, al no ofrecerse argumentos que justifiquen el cambio de la misma. Damos por reproducidos los argumentos que se dan en esas sentencias que pueden resumirse diciendo que de los artículos 7, 48-1 y 51 del E.B.E.P. (RCL 2007, 768) se deriva que la normativa laboral y los convenios colectivos son aplicables con preferencia a los preceptos citados del E.B.E.P. Porque como en esas sentencias se afirma: "del art. 51 EBEP y de la remisión que efectúa para el régimen de permisos del personal laboral "a lo establecido en este Capítulo y en la legislación laboral correspondiente" no entendemos que se pueda interpretar que deba ser aplicada en todo caso y con preferencia absoluta la normativa estatutaria sobre la convencional en materia de permisos." (FJ. Segundo).

44 En ese sentido, Vid. De Sande Perez-Bedmar, María, “Empleo público local”, Anuario de derecho municipal 2007, IDL-Universidad Autónoma de Madrid, Madrid, 2007 (págs. 314 y 315). 
ellos necesita del complemento (desarrollo) legislativo -circunstancia que Martín Rebollo45 ha venido a denominar "el complemento indispensable del legislador, estatal o autonómico, de desarrollo"-. Hasta que dicho complemento se apruebe y a fin de evitar el vacío normativo, la disposición final cuarta prevé que se mantengan en vigor en cada Administración Pública, "las normas vigentes sobre ordenación, planificación y gestión de recursos humanos en tanto no se opongan a lo establecido en este Estatuto", lo que en realidad condiciona la vigencia de estos artículos del EBEP a lo que disponía la legislación preexistente. A ello cabe añadir los problemas de encaje que en ocasiones dicha operación plantea. Por tanto, en realidad la vigencia de algunos de estos preceptos no es "plena".

En relación con las disposiciones que no han entrado en vigor, el legislador -como ha señalado la doctrina ${ }^{46}$ ha creado una nueva clase de bases, "las bases diferidas", que tendrán eficacia una vez se desarrollen. Este tipo de bases, quizá pudiera tener un difícil encaje con la jurisprudencia constitucional ${ }^{47}$, ya que ésta, hasta la fecha, no ha contemplado la existencia de un concepto legal de "bases" que implique que la regulación estatal resulte ineficaz hasta que no exista regulación autonómica de desarrollo.

En todo caso, el posterior desarrollo o adaptación normativa, corresponderá a los respectivos legisladores, de conformidad con los títulos competenciales a los que se ha hecho referencia en el apartado anterior de este trabajo.

En suma, a pesar del tiempo transcurrido, y de la necesidad de que se aprueben normas de desarrollo para que algunos apartados del Estatuto puedan cobrar vigencia plena -o simplemente, entrar en vigor-, a día de la fecha su desarrollo -como se expondrá a continuación-, ha sido escaso y fragmentario.

\section{b) El desarrollo estatal}

Hasta la fecha, por parte del Estado apenas se han aprobado disposiciones de desarrollo del EBEP, ni de carácter básico -en uso de los distintos títulos competenciales expresados con anterioridad-, ni tampoco dirigidas exclusivamente a la propia Administración estatal ${ }^{48}$; y como se expondrá las pocas que se han aprobado, han tenido un carácter muy puntual, y de éstas, algunas están íntimamente vinculadas a medidas presupuestarias adoptadas como consecuencia de la situación económico financiera actual.

Desde la óptica local, entre las medidas de desarrollo puntual cabría hacer mención a un mínimo desarrollo de la disposición adicional segunda, en lo que respecta al régimen de selección de la Escala de Funcionarios con habilitación de carácter estatal 49 .

También han tenido incidencia directa en el ámbito local, las modificaciones puntuales del EBEP que a lo largo de este periodo de tiempo se han aprobado por las Cortes Generales, entre ellas, cabe destacar las relativas a situaciones administrativas (modificación del artículo 87.1 e), en relación a la situación de servicios especiales); reserva de discapacitados (modificación del artículo 59.1, en lo relativo a la reserva de un cupo no inferior al siete por ciento de las vacantes, para ser cubiertas entre personas con discapacidad -de éstas, el dos por ciento por personas que acrediten discapacidad intelectual-; permisos y licencias (modificaciones en el artículo 49e) estableciendo el permiso por cuidado de hijo menor afectado por cáncer u otra enfermedad grave); o la relativa a la Escala de funcionarios con habilitación de carácter estatal (modificación del apartado 5 de la disposición adicional segunda, en materia de provisión de puestos de trabajo reservados -concurso ordinario y libre designación-).

Entre las modificaciones del EBEP íntimamente vinculadas a medidas presupuestarias cabe destacar las practicadas por el Real Decreto-ley 20/2012, de 13 de julio, de medidas para garantizar la estabilidad presupuestaria y de fomento de la competitividad. Dicha norma ha alterado el EBEP en sus artículos 32 (en materia de negociación colectiva del personal laboral); 48 (permisos de los funcionarios públicos) y 50 (vacaciones de los funcionarios públicos), además de diversos preceptos básicos que inciden en el régimen de los empleados públicos, como por ejemplo, en lo referente a la prestación económica en la situación de incapacidad temporal ${ }^{50}$.

45 Martín Rebollo, Luís, El Estatuto del Empleado Público: Un Godot que no ha llegado”, Revista de Administración Pública, núm. 174, Madrid, septiembre-diciembre (2007), págs. 129-159. (pág. 130).

46 Álvarez Rico, Manuel, González-Haba Guisado, Vicente $M^{a}$ y Orduña Prada, Enrique, Administración y empleo público en España, CEMCI-Diputación Provincial de Granada, Granada, 2011 (pág. 362).

47 Sentencia del Tribunal Constitucional 1/1982, de 28 de enero (RTC 1982/1).

48 Entre éstas últimas puede destacarse por ejemplo, la ampliación de la duración del permiso de paternidad en los casos de nacimiento, adopción o acogida, implementada por la Ley 9/2009, de 6 de octubre, cuya vacatio legis se ha pospuesto hasta el 1 de enero de 2013 (en virtud del Real Decreto-ley 20/2011, de 30 de diciembre, de medidas urgentes en materia presupuestaria, tributaria y financiera para la corrección del déficit público).

49 Orden APU/450/2008, de 31 de enero, por la que se aprueban los títulos académicos y programas mínimos requeridos para el acceso a las Subescalas en que se estructura la Escala de funcionarios con habilitación de carácter estatal (publicada en el Boletín Oficial del Estado núm. 48, de 25 de febrero de 2008), modificada por Orden APU/3805/2008, de 26 de diciembre (publicada en el Boletín Oficial del Estado núm. 315, de 31 de diciembre de 2008).

50 Son de relevante interés en la materia los “Criterios para la aplicación del Título I del Real Decreto Ley 20/2012, de 13 de julio, para garantizar la estabilidad presupuestaria y de fomento de la competitividad, en el ámbito de las Comunidades Autónomas y de las Entidades Locales" fijados por la Dirección General de la función Pública del Ministerio de Hacienda y Administraciones Públicas. 
A las anteriores medidas hay que sumar, en lo que respecta al régimen jurídico del personal laboral al servicio de las Administraciones Públicas, las medidas contenidas en la Ley 3/2012, de 6 de julio, de medidas urgentes para la reforma del mercado laboral ${ }^{11}$ (con sus disposiciones adicionales segunda, tercera y octava especialmente dirigidas a las Administraciones Públicas).

En ese sentido, es reseñable también que ciertas medidas vinculadas a disposiciones presupuestarias, están produciendo una extensión de la legislación básica en materia de empleo público -y que en consecuencia van más allá de las previsiones contenidas en el EBEP-. En ese sentido, por ejemplo cabe destacar que la última Ley de Presupuestos Generales del Estado52, en su disposición adicional septuagésima primera rotulada "Jornada de Trabajo", determina con carácter básico la jornada mínima general de trabajo en el sector público 53 . En esa línea también se sitúa la modificación del EBEP en materia vacaciones y permisos practicada por el art. 8 del RD-ley 20/2012, ya que no sólo amplía el contenido y sentido de las bases para el personal funcionario, sino que también el punto tres del art. 8, hace extensivas determinadas cuestiones de dicho régimen al personal laboral al servicio de las Administraciones Públicas, lo que supone -de facto- una modificación del alcance del artículo 51 del EBEP en la interpretación ofrecida por el Tribunal Supremo.

En suma, desde la perspectiva de la Administración Local, el desarrollo o adaptación de la legislación estatal al EBEP ha sido prácticamente inexistente y, en su caso, centrado en aspectos muy puntuales, circunstancia que en determinados supuestos provoca inseguridad jurídica acerca del alcance que actualmente tiene alguno de los preceptos sobre función pública integrados en el bloque de legislación básica de régimen local.

El Tribunal Constitucional (STC 1/1982, de 28 enero) ha afirmando respecto a la legislación básica que,

"Dado su carácter general y fundamental respecto al resto de la ordenación de la materia, las bases de la misma deben tener estabilidad, pues con ellas se atiende a aspectos más estructurales que coyunturales" (F. J. $\left.1^{\circ}\right)$.

En ese sentido, también resulta necesario que se efectúe dicha adaptación, en atención a la incertidumbre que genera desconocer cuál va a ser la configuración que tras el EBEP va a tener la legislación básica en materia de empleo público local. Si actualmente se desarrolla el EBEP por una Comunidad Autónoma, determinadas alteraciones posteriores sobre la legislación básica -conforme la reciente interpretación del Tribunal Constitucional ${ }^{54}$ sobre la inaplicabilidad del principio de prevalencia de la legislación estatal-, podrían llegar a provocar un nada deseable aumento de la litigiosidad, o como Javier Delgado Barrio5s ha señalado, "un complejo peregrinaje procesal -de ida al Juzgado de lo ContenciosoAdministrativo, de vuelta al Tribunal Constitucional y otra vez de ida a dicho Juzgado-".

A ello hay que añadir importantes limitaciones, como por ejemplo, las que genera la falta de adaptación de la legislación básica al nuevo Grupo B de clasificación profesional del personal funcionario de carrera, creado por el artículo 76 EBEP.

A pesar de los problemas que provoca la situación actual, en el futuro más inmediato ésta parece que se va a mantener, ya que si bien ${ }^{56}$ el Gobierno prevé ejercer la iniciativa legislativa en determinados ámbitos que pueden tener incidencia en materia de empleo público -entre ellos, en el ámbito local-, no parece figurar entre ellos abordar de un modo integral la cuestión del marco jurídico del empleo público -en ejercicio de sus distintos títulos competenciales-. No obstante, sí cabe destacar la previsión de aprobar un proyecto de "Ley para la racionalización y sostenibilidad de la Administración Local”, que -entre otras cuestiones- podría incidir en materia de empleo público local57.

51 Ley que tiene fundamento en el Real Decreto-ley 3/2012, de 10 de febrero, de medidas urgentes para la reforma del mercado laboral, convalidado por Resolución de 8 de marzo de 2012, del Congreso de los Diputados, por la que se ordena la publicación del Acuerdo de convalidación del Real Decreto-ley 3/2012, de 10 de febrero, de medidas urgentes para la reforma del mercado laboral.

52 Aprobados por Ley 2/2012, de 29 de junio, de Presupuestos Generales del Estado para el año 2012.

53 No obstante, a efectos de la Administración local, la jornada permanece regulada dentro de los parámetros establecidos en el artículo 94 de la LRBRL.

54 Sentencia del Tribunal Constitucional 66/2011, de 16 de mayo (publicada en el Boletín Oficial del Estado, núm. 139 , de 11 de junio de 2011).

55 En el voto particular que este magistrado realiza.

56 En ese sentido, vid. el "Informe sobre el plan de reformas para el segundo semestre de 2012" sobre el calendario del Programa Nacional de Reformas para el segundo semestre, analizado en el Consejo de Ministros celebrado el 13 de julio de 2012.

57 Según referencia del Consejo de Ministros de 13 de julio de 2012, y borrador del anteproyecto de "Ley para la racionalización y sostenibilidad de la Administración Local” (versión 26.07.12). Ésta afectaría esencialmente, a la escala de funcionarios con habilitación de carácter estatal, todo ello sin perjuicio -como se ha indicado anteriormente-, de una posible nueva redacción del artículo 92.1 de la LRBRL, y de determinadas modificaciones puntuales en relación con el personal directivo de las Diputaciones Provinciales, Cabildos y Consejos Insulares, y en relación con el personal eventual. 


\section{c) El desarrollo autonómico}

En lo que respecta a las Comunidades Autónomas, únicamente la Comunidad Valenciana y la de Castilla-La Mancha, han efectuado un desarrollo legislativo del EBEP que podría calificarse como integral, incluyendo a las entidades que integran la Administración Local dentro de sus respectivos ámbitos de aplicación.

Las restantes Comunidades, o bien no ha acometido desarrollo legislativo alguno, o bien han desarrollado aspectos muy puntuales del EBEP, orientando su aplicación -principalmente- hacia la Administración autonómica. Dentro de estas últimas, cabe incluir también las distintas normas que las comunidades autónomas -al igual que el Estado- están aprobando en los últimos meses en materia presupuestaria. Aunque la mayoría de ellas están dirigidas fundamentalmente al Sector Público autonómico, también pueden llegar a tener incidencia en el ámbito local -por vía de la remisión a través de la legislación de régimen local, a lo que en ese sentido disponga la legislación autonómica- ${ }^{58}$.

Ello nos permite adelantar que, en términos generales, la incidencia que el desarrollo legislativo autonómico del EBEP ha tenido sobre el régimen jurídico del empleo público local ha sido muy limitada-sin perjuicio de las dos excepciones indicadas-, y con efectos dispares que dependerán, tanto del ámbito de aplicación de la normativa de desarrollo, como del tipo de disposiciones que conformasen previamente el referido régimen jurídico.

Con carácter general, un desarrollo integral de la normativa básica por parte del legislador autonómico, tendría los siguientes efectos sobre el sistema de fuentes local: de una parte daría plena vigencia a la totalidad del articulado del EBEP; y de otra, simplificaría el ordenamiento jurídico ya que provocaría la exclusión del sistema de fuentes -allí donde sean de aplicación-, de aquellos preceptos estatales que tienen carácter supletorio.

Seguidamente, se enumeran algunas de las normas que las Comunidades Autónomas han aprobado en desarrollo del EBEP, prestando especial atención a si éstas incluyen en sus respectivos ámbitos de aplicación a las Entidades Locales. Asimismo, también se hace una breve reseña sobre la normativa aprobada por las Comunidades Autónomas, en desarrollo del nuevo régimen jurídico de los funcionarios con habilitación de carácter estatal, establecido en la disposición adicional segunda del EBEP.

\section{- Galicia}

Galicia fue la primera comunidad en iniciar la adaptación de su normativa al EBEP. Antes de la entrada en vigor del Estatuto, la legislación propia de la Comunidad Autónoma de Galicia en materia de función pública venía constituida esencialmente por la Ley 4/1988, de 26 de mayo, de la función pública de Galicia, norma que incluía al personal de la Administración Local en su ámbito de aplicación directa, pero que apenas tenía preceptos dedicados a éste.

Hasta la fecha, la adaptación de la legislación gallega al EBEP se ha efectuado fundamentalmente por dos normas. En primer lugar, y con carácter prácticamente simultáneo a la entrada en vigor del EBEP, la Comunidad aprobó una modificación en la citada Ley 4/1988, de 26 de mayo, mediante la Ley 13/2007, de 27 de julio. En una segunda fase, la adaptación al EBEP vino de la mano de la Ley 15/2010, de 28 de diciembre, de medidas fiscales y administrativas.

En cuanto a la Ley 13/2007, de 23 de julio, en su exposición de motivos señalaba que "aprobado el Estatuto del empleado público, los poderes públicos de Galicia deben, entre tanto, comenzar inmediatamente a aplicar una serie de medidas urgentes para la mejora y racionalización del empleo público autonómico." Esta norma, en su disposición final primera contenía un mandato para refundir la normativa vigente en materia de función pública, a lo que el ejecutivo autonómico dio cumplimiento mediante el Decreto Legislativo 1/2008, de 13 de marzo, por el que se aprueba el texto refundido de la Ley de la función pública de Galicia (TRLFPG, en adelante), norma vigente a día de la fecha, con las modificaciones a las que se harán referencia más adelante.

En cuanto al ámbito de aplicación del TRLFPG, el artículo 3.2 señala que "en lo que no está reservado a la legislación del Estado, se aplicará esta ley al personal de la Administración local”. A pesar de que la norma contempla al personal al servicio de la Administración Local dentro de su ámbito de aplicación -algo que no todas las Comunidades Autónomas efectúan-; desde la óptica local, la configuración de la norma no satisface de la mejor manera posible el principio de seguridad jurídica. En ese sentido, la mayor parte de sus preceptos hacen referencia exclusiva a la Administración de la comunidad o a órganos de la misma, de lo que se deduce que dicha norma está concebida fundamentalmente para el personal a su servicio, siendo residuales los preceptos que hacen referencia a las Administraciones incluidas en su ámbito de aplicación -a todas-, o a las entidades que integran la Administración Local.

58 Entre estas, por ejemplo, la Ley 5/2012, de 29 de junio, de ajuste presupuestario y de medidas en materia de Función Pública (publicada en el Boletín Oficial de la Región de Murcia núm. 150, de 30 de junio de 2012). 
El desarrollo efectuado por la Ley 13/2007, de 27 de julio tiene carácter parcial, afectando entre otras materias, a la regulación de determinadas cuestiones relativas a las clases de empleados públicos; registros de personal -donde por cierto se hace alusión expresa (artículo 23) a la cooperación entre la Administración autonómica y las Entidades Locales para su constitución-; selección; provisión de puestos de trabajo; vacaciones y permisos; y aunque la carrera profesional no se aborda, sí se regula la evaluación del desempeño.

Con posterioridad al TRLFPG, la Ley de 15/2010, de 28 de diciembre, de medidas fiscales y administrativas, volvió a adaptar "la legislación de función pública a lo dispuesto en el Estatuto básico del empleado público" -en esos términos consta en la exposición de motivos-, si bien, nuevamente la adaptación es muy puntual, versando sobre cuestiones relativas a selección, provisión, planificación y situaciones administrativas.

Además de por la anterior, el TRLFPG también ha sido modificado por otras normas. Una primera modificación -directamente aplicable a las Entidades Locales-, fue la practicada en su artículo 35 por la Ley 2/2009, de 23 de junio, en materia de selección -conocimiento del gallego-. Asimismo, recientemente la Ley 1/2012, de 29 de febrero, de medidas temporales en determinadas materias del empleo público de la Comunidad Autónoma de Galicia, ha introducido determinadas medidas en esta materia ${ }^{59}$, sin que las entidades que integran la Administración Local estén directamente incluidas en el ámbito de aplicación (artículo 1) de la norma.

En conclusión, a pesar de que en estudios editados por la propia Comunidad Autónoma se proponía la creación de un título propio dedicado de forma específica a la función pública local, en el que se desarrollasen las previsiones "tanto del EBEP como de la legislación básica de régimen local”60, estas propuestas no se han asumido, y como se ha expuesto, la Comunidad ha apostado por mantener al empleo público local incluido dentro del ámbito de aplicación directa de la normativa autonómica, lo que provoca que ésta en determinadas materias posea como ya se venía reconociendo- "un grado más bien reducido de eficacia práctica"61.

\section{- Principado de Asturias}

En la Comunidad Autónoma del Principado de Asturias, la vigente Ley 3/1985, de 26 de diciembre, de ordenación de la Función Pública, es una norma dirigida únicamente a la Administración de la Comunidad Autónoma (artículo 1), sin perjuicio de su aplicación a las entidades que integran la Administración Local, en virtud de la remisión que se efectúa desde la normativa de régimen local.

A pesar de lo indicado, conviene hacer siquiera una breve referencia a las normas con rango de ley que ha aprobado esa comunidad en desarrollo del EBEP. Así, en primer término se aprobó la Ley 5/2009, de 29 de diciembre $^{62}$, una norma que implementó la carrera horizontal y la evaluación del desempeño en el ámbito de la Administración autonómica, y que ya cuenta con un completo desarrollo reglamentario ${ }^{63}$.

En segundo lugar, la Ley 14/2010, de 28 de diciembre ${ }^{64}$, ha introducido modificaciones puntuales en materia de provisión de puestos de trabajo -fundamentalmente en los sistemas de libre designación, concurso de méritos y comisiones de servicios-, adaptando y desarrollando la normativa autonómica a lo establecido por el EBEP.

Por ello, si bien el desarrollo efectuado del EBEP ha sido novedoso y trascendente, éste lo ha sido sobre aspectos muy puntuales y enfocados únicamente a la Administración de la Comunidad Autónoma.

\section{- Comunidad Valenciana}

Desde una perspectiva local, el desarrollo legislativo del EBEP en la Comunidad Valenciana se ha articulado principalmente a través dos leyes, aprobadas de forma casi simultánea en el tiempo. Así, por un lado la Comunidad, en uso del título competencial contemplado en el artículo 50.1 de su Estatuto de Autonomía -régimen estatutario de sus funcionarios-, ha desarrollado el EBEP de modo general en la Ley 10/2010, de 9 de julio, de ordenación y gestión de la Función Pública Valenciana. Por otro lado, la Comunidad, en uso de sus competencias en materia de régimen local -reconocidas entre otros en los artículos 49.1.8 y 64.1 del Estatuto de Autonomía-, desarrolló sectorialmente el EBEP a través de la Ley 8/2010, de 23 de junio, de Régimen Local de la Comunidad Valenciana.

59 Según su propia Exposición de Motivos, son medidas "extraordinarias, urgentes y de carácter temporal en materia de contención de gastos en el capítulo I de los presupuestos de la Comunidad Autónoma de Galicia."

60 AA.VV., Documentos para la reforma de la función pública. Xunta de Galicia. La Coruña, 2008, pág. 27.

61 Ibidem.

62 Ley 5/2009, de 29 de diciembre, de séptima modificación de la Ley 3/1985, de 26 de diciembre, de ordenación de la Función Pública, para la regulación de la carrera horizontal.

63 El desarrollo se ha producido por el Decreto 37/2011, de 11 de mayo, por el que se aprueba el Reglamento de la carrera horizontal de la Administración del Principado de Asturias.

64 Ley 14/2010, de 28 de diciembre, de octava modificación de la Ley 3/1985, de 26 de diciembre, de ordenación de la Función Pública. 
Desde el punto de vista local, la Ley de Función Pública Valenciana incluye indubitadamente dentro de su ámbito de aplicación (artículos 3 y 5) a las Entidades Locales ${ }^{65}$ así como -con diferentes grados de intensidad-a su respectivo sector público ${ }^{66}$.

La norma está redactada con referencia a la estructura orgánica de la Administración de la Comunidad Autónoma, si bien, el artículo 11 efectúa una adaptación general de su articulado a los órganos competentes de las Entidades Locales.

De ella se puede predicar que tiene la virtud de ser la primera disposición con rango de ley que efectúa un desarrollo integral del EBEP (clases de personal, estructura y ordenación del empleo público, situaciones administrativas ${ }^{67}$, adquisición y pérdida de la condición de empleado público, etc.) Ahora bien, la vigencia del régimen retributivo y de la seguridad social, así como de la promoción profesional, ha quedado demorada hasta la entrada en vigor de las normas reglamentarias que los desarrollen. En idénticos términos también se demora la entrada en funcionamiento del Consejo Asesor de la Función Pública Valenciana, órgano que tiene encomendado el análisis, estudio y asesoramiento en materia de empleo público, y en el que estarán representadas las Entidades Locales.

Aunque en la Comunidad Autónoma existe un cierto número de municipios ${ }^{68}$ con capacidad para poder desarrollar determinadas políticas propias en materia de empleo público, la capacidad de otros muchos es limitada. Por ello, en su articulado quedan apuntadas también posibles vías de cooperación entre la comunidad autónoma y las Entidades Locales, como por ejemplo para la elaboración de relaciones de puestos de trabajo (artículo 41.3) o para constitución de registros de personal (artículo 47.2). En este sentido se crea un Registro autonómico de puestos de trabajo de las Entidades Locales (artículo 50) radicado en la Consejería competente en materia de Administración Local.

Por último, en lo que se refiere a la estructura de empleo público -cuerpos y escalas-, el artículo 31 supone la adecuación de la ley autonómica, a lo que disponga la normativa básica de régimen local -radicada en la actualidad esencialmente en el Texto Refundido de las Disposiciones Legales vigentes en materia de Régimen Local-.

En lo que respecta a la Ley de Régimen Local de la Comunidad Valenciana, ésta contiene un título dedicado al personal al servicio de las Entidades Locales -el noveno-, si bien, en él además de otras cuestiones, esencialmente se regulan determinados aspectos del régimen jurídico de los funcionarios con habilitación de carácter estatal como la creación y clasificación de puestos, selección, provisión y régimen disciplinario-. ${ }^{69}$

No obstante lo anterior, también durante este periodo se han aprobado otras leyes sectoriales que -en conexión con el EBEP-, han tenido incidencia directa en el marco jurídico del empleo público local, como por ejemplo la Ley 7/2011, de 1 de abril, de los Servicios de Prevención, Extinción de Incendios y Salvamento de la Comunidad Valenciana, que amparándose en la competencia autonómica en materia de régimen local y régimen estatutario de sus funcionarios (artículos 49.1.8 y 50.1 del Estatuto de Autonomía), establece la estructura y régimen de funcionamiento de los servicios de prevención y extinción de incendios -entre ellos, de los que son titularidad local-, regulando cuestiones como las particularidades de estructura organizativa y funcional; requisitos y sistemas de acceso por escalas y categorías; promoción; movilidad; segunda actividad; derechos y deberes; o el régimen disciplinario.

65 La ahora derogada Ley de Función Pública de Comunidad Valenciana, aprobada por Decreto Legislativo de 24 de octubre 1995 , también incluía en su ámbito de aplicación (artículo 1) "al personal de la Administración Local que no sea habilitado de carácter nacional".

66 En ese sentido, la disposición adicional séptima de la Ley de ordenación y gestión de la Función Pública Valenciana, dispone cómo queda conformado es el régimen jurídico aplicable al personal funcionario con habilitación de carácter estatal, así como al personal de los Cuerpos de Policía Local.

67 En ese sentido, los apartados 1 b) y 4 del artículo 130 -que regula la situación administrativa de excedencia voluntaria por cuidado de familiares-, se encuentran en suspenso a día de la fecha como consecuencia del recurso de inconstitucionalidad 7456-2010 promovido por el Presidente del Gobierno (Auto del Tribunal Constitucional de 12 de abril de 2011, publicado en el Boletín Oficial del Estado núm. 94, de 20 de abril de 2011 y posterior corrección de errores).

68 Estructura municipal en la Comunidad Valenciana:

\begin{tabular}{|l|l|}
\hline Tramos de población & Núm. municipios \\
\hline Hasta 2.000 habitantes & 301 \\
\hline De 2.000 a 5.000 habitantes & 82 \\
\hline De 5.000 a 30.000 habitantes & 128 \\
\hline De 30.000 a 100.000 habitantes & 26 \\
\hline De 100.000 habitantes en adelante & 5 \\
\hline TOTAL & 542 \\
\hline
\end{tabular}

Estructura municipal Comunidad Valenciana. Elaboración propia. Fuente: Registro Entidades Locales. MINHAP. 1 de junio de 2012.

69 En ese sentido, destacar que la redacción del artículo 104.2 de la Ley de Régimen Local de la Comunidad Valenciana (relativo a atribución de las funciones de contabilidad, tesorería y recaudación en mancomunidades de municipios), fue modificado por acuerdo de la Comisión Bilateral de Cooperación entre la Administración General del Estado y la Generalidad Valenciana, al colisionar su redacción inicial con la disposición adicional segunda del EBEP (publicado en el Boletín Oficial del Estado núm. 98, de 25 de abril de 2011). 


\section{- Castilla-La Mancha}

La Ley 4/2011, de 10 de marzo, del Empleo Público de Castilla-La Mancha, fue aprobada por la Comunidad Autónoma en uso de los títulos competenciales para el establecimiento del régimen estatutario de sus funcionarios y en materia de régimen local70. En ese sentido, la norma incluye en su ámbito de aplicación (artículo 2) a las Entidades Locales de Castilla-La Mancha -así como a su sector público-, teniendo carácter supletorio para el personal funcionario de los Cuerpos de Policía Local y de Bomberos, y para los funcionarios con habilitación de carácter estatal.

En primer término, dejando al margen su contenido concreto, cabe reconocer a esta norma la virtud de sistematizar una parte importante la normativa aplicable, facilitando así la labor del operador jurídico, que antes había de integrar numerosos textos asistemáticos y fragmentados.

Esta ley efectúa un desarrollo integral del EBEP, abordando cuestiones como el régimen jurídico del personal al servicio de las AA.PP., la ordenación de la actividad profesional, el acceso al empleo público y pérdida de la relación de servicio, la carrera profesional, provisión de puestos de trabajo, régimen disciplinario, etc.

Sin perjuicio de la existencia de determinados preceptos dirigidos únicamente a la Administración de la Junta de Comunidades de Castilla-La Mancha, la mayor parte de los preceptos de la norma están redactados haciendo alusión a las “Administraciones públicas de Castilla-La Mancha”. Esta técnica legislativa parece más adecuada que la empleada por la Comunidad Valenciana, ya que facilita la exégesis de la norma, al discriminarse fácilmente qué preceptos son de aplicación exclusiva a la comunidad autónoma, y cuales están dirigidos a todas las Administraciones Públicas incluidas en su ámbito de aplicación.

La Comunidad Autónoma de Castilla-La Mancha, tiene un alto número de municipios ${ }^{71}$, buena parte de los cuales -en atención a su reducido tamaño- tienen una capacidad limitada para poder aplicar determinados instrumentos de gestión en materia de recursos humanos. Ello exige un cierto grado de flexibilidad, de la que se ha dotado a la norma en cuestiones como por ejemplo la regulación de la carrera profesional horizontal. Asimismo, la norma también ha contemplado posibles vías de cooperación y colaboración entre la Junta de Comunidades y las Entidades Locales, para la constitución de registros de personal (artículo 20), o en materia de selección (artículo 50), además de contar con un título específico -el XII-, dedicado a la cooperación entre las Administraciones Públicas de Castilla-La Mancha.

Cabe destacar que en materia de cuerpos de personal funcionario de las Entidades Locales, el artículo 34 efectúa una remisión directa a la legislación de régimen local -en lógica correspondencia con su carácter básico-, si bien, prevé la posibilidad de que pueda agruparse en un futuro de forma similar a la prevista para la Administración de la Junta de Comunidades de Castilla-La Mancha. La doctrina ha señalado que ello se debe "al margen de incertidumbre que presenta el sistema de fuentes previsto en el artículo 3 del EBEP"72, y al objeto de facilitar la movilidad interadministrativa en el ámbito de la Comunidad Autónoma.

Por último, en cuanto a los funcionarios con habilitación de carácter estatal, la norma desarrolla en la disposición adicional decimoséptima, determinados aspectos de su régimen jurídico referidos al acceso y al régimen disciplinario.

\section{- Otras iniciativas para el desarrollo del EBEP}

Otras iniciativas para desarrollar integralmente el EBEP, se quedaron por el camino en diferentes estadios previos a su aprobación. Así le acaba de suceder al proyecto "Proyecto de Ley del empleo público de Euskadi”"73, que

70 Contempladas, respectivamente, en los artículos 39.3 y 32.1 del Estatuto de Autonomía de Castilla-La Mancha.

71 Estructura municipal de la Comunidad Autónoma de Castilla-La Mancha:

\begin{tabular}{|l|l|}
\hline Tramos de población & Núm. municipios \\
\hline Hasta 2.000 habitantes & 726 \\
\hline De 2.000 a 5.000 habitantes & 118 \\
\hline De 5.000 a 30.000 habitantes & 64 \\
\hline De 30.000 a 100.000 habitantes & 11 \\
\hline De 100.000 habitantes en adelante & 1 \\
\hline TOTAL & 920 \\
\hline
\end{tabular}

Estructura municipal Castilla-La Mancha. Elaboración propia. Fuente: Registro Entidades Locales. MINHAP. 1 de junio de 2012.

72 Cantero Martínez, Josefa, “Estructura y ordenación del Empleo Público en las Administraciones de Castilla-La Mancha”, en Revista Jurídica de Castilla-La Mancha, Junta de Comunidades de Castilla-La Mancha, núm. 50, diciembre de 2011, p. 71.

73 Publicado en el Boletín Oficial del Parlamento Vasco, núm. 177 -IX legislatura-, de 31 de agosto de 2012. 
no ha podido proseguir su tramitación ya que por Decreto 12/2012, de 27 de agosto, del Lehendakari74, se disolvió el Parlamento Vasco y se procedió a la convocatoria de elecciones.

Aunque buena parte de sus preceptos están referidos a las Administraciones Públicas vascas, este concepto -según establece el artículo 3, en su apartado 2, letras a) y b) y en su apartado 3-, incluye también a las entidades que integran la Administración Local que están situadas dentro del ámbito territorial de la comunidad autónoma del País Vasco, a saber: las administraciones forales de los territorios históricos (Diputaciones Forales), las restantes entidades que integran la Administración Local, así como su respectiva Administración institucional y los demás entes instrumentales con personalidad jurídica propia, vinculados o dependientes éstas (todo ello, sin perjuicio de que el artículo 7 también prevé la aplicación de determinados principios, para las restantes entidades que componen el sector público local, no incluidas dentro de las enumeradas). En ese sentido, el artículo 4 del proyecto determina cuál es el concreto el sistema de fuentes de aplicación al personal de la Administración foral y local.

La norma efectúa una regulación integral de la práctica totalidad de las materias que afectan al empleo público (con importantes novedades entre otras cuestiones, en carrera profesional y régimen retributivo, evaluación del desempeño, situaciones administrativas, provisión de puestos, o en la regulación de la dirección pública profesional), estableciendo en la regulación determinadas particularidades en su aplicación para las entidades que integran la Administración Local. Asimismo, el artículo 62 contiene una regulación particular del personal funcionario con habilitación de carácter estatal, desarrollando el EBEP.

Tampoco salió adelante el proyecto de ley presentado en la Comunidad Autónoma de las Illes Balears ${ }^{75}$, bajo la denominación de "Ley de Función Pública de las Administraciones de las Illes Balears". En su ámbito de aplicación estaban contempladas las "administraciones de los Consejo Insulares y de las restantes Entidades Locales de la Comunidad Autónoma”, incluyendo además un título con normas específicas para la Administración Local ${ }^{76}$.

Por último, tampoco fructificaron en las Comunidades Autónomas de Cantabria y de Aragón sus iniciativas para desarrollar el EBEP, que se quedaron a nivel de anteproyecto de ley. Desde el punto de vista local, el anteproyecto de "Ley de Función Pública de Cantabria", preveía ser de aplicación supletoria "al personal de las Entidades Locales de Cantabria”. Por el contrario, el anteproyecto de "Ley de Empleo Público de Aragón” contemplaba expresamente dentro de su ámbito de aplicación a las “administraciones de las Entidades Locales aragonesas”.

\section{- Especial referencia a los funcionarios con habilitación de carácter estatal}

Los funcionarios con habilitación de carácter estatal son el colectivo de empleados públicos que presta servicios en las Entidades Locales, para los que la entrada en vigor del EBEP ha supuesto de modo directo, la mayor alteración en su régimen jurídico regulador.

Si bien las funciones cuyo desempeño tienen reservado continúan siendo las mismas que tenían, la disposición adicional segunda del Estatuto ha supuesto la transferencia directa del Estado a las Comunidades Autónomas de nuevas y mayores competencias sobre su régimen jurídico -normativas y de ejecución-, entre otras, en materia de selección y carrera profesional -promoción interna-, provisión de puestos de trabajo reservados -concurso ordinario-, registro de personal y régimen disciplinario.

Desde el punto de vista normativo, a día de la fecha, sólo una parte de las Comunidades Autónomas ha procedido a desarrollar el régimen jurídico aplicable a esta Escala de funcionarios, desplazando así, al menos de manera parcial -en aquellos aspectos que no posean carácter básico-, a la normativa estatal -que permanece vigente en los términos expresados en la disposición transitoria séptima del EBEP-. De este modo, además de los desarrollos efectuados a través de normas con rango de ley, por la Comunidad Valenciana o por Castilla-La Mancha -ya indicados-; algunas comunidades como Cataluña77, Galicia $^{78}$, o muy recientemente la Región de Murcia79, han aprobado disposiciones que contienen una

74 Publicado en el Boletín Oficial del País Vasco núm. 167, de 28 de agosto de 2012.

75 Publicado en el Boletín Oficial del Parlamento de las Illes Balears núm. 128/1, de 21 de mayo de 2010.

76 No obstante lo anterior, con posterioridad, el referido proyecto se ha presentado a su tramitación bajo la forma de “Proposición de ley, de función pública de les Administraciones de las Illes Balears".

77 Decreto 195/2008, de 7 de octubre, del Departamento de Gobernación y Administraciones Públicas, por el que se regulan determinados aspectos del régimen jurídico del personal funcionario con habilitación de carácter estatal de las Entidades Locales de Cataluña.

78 Decreto 49/2009, de 26 de febrero, de la Consejería de Presidencia, Administraciones Públicas y Justicia, por el que se regula el ejercicio de las competencias de la Comunidad Autónoma de Galicia respecto de los/las funcionarios/as con habilitación de carácter estatal.

79 Decreto 58/2012, de 27 de abril, del Consejo de Gobierno, por el que se regula el régimen jurídico de los funcionarios con habilitación de carácter estatal. 
regulación prácticamente integral de la Escala. Otras como La Rioja ${ }^{80}$, Extremadura ${ }^{81}$, Andalucía ${ }^{82}$, o las Illes Balears ${ }^{83}$, únicamente han aprobado disposiciones que regulan materias puntuales.

No obstante lo anterior, como se indicaba anteriormente, existe la previsión de aprobar un proyecto de ley que, entre otras cuestiones, podría modificar el régimen jurídico que regula la Escala de funcionarios con habilitación de carácter estatal ${ }^{84}$.

\section{CONCLUSIÓN}

La incidencia del EBEP sobre la Administración Local, queda profundamente condicionada en numerosas materias, por el ejercicio de desarrollo que efectúe el legislador. El artículo 3.1 del EBEP ha establecido un sistema de fuentes que da cobertura a la "doble competencia" estatal en materia de función pública local y, como consecuencia -junto a otras disposiciones básicas-, permanecen vigentes en todo aquello que no contradigan al EBEP, las disposiciones reguladoras del empleo público integradas dentro del bloque normativo básico del régimen local. A las comunidades autónomas les corresponderá -en uso de sus distintos títulos competenciales- el desarrollo de la legislación básica, debiendo observarse, en todo caso, el principio de autonomía local.

A pesar del tiempo transcurrido desde su aprobación, lo cierto es que ni el legislador estatal ni los de la mayor parte de las comunidades autónomas, han acometido el desarrollo o acomodamiento de su normativa a lo dispuesto en el EBEP.

Ello provoca además de inseguridad jurídica-como consecuencia del no siempre fácil encaje de la normativa previa a la nueva regulación del EBEP-, que el propio Estatuto todavía no haya entrado en vigor para un buen número de empleados públicos en una parte significativa de su articulado.

En el informe suscrito por la Comisión para el estudio y preparación del EBEP ${ }^{85}$, que data de abril de 2005, entre otras cuestiones se ponían de manifiesto una serie de notas características y también de problemas ${ }^{86}$ propios de la Administración Local. Uno de estos problemas era la "relativa inseguridad jurídica sobre la legislación aplicable a los funcionarios locales".

En efecto, con carácter previo al EBEP la normativa estaba dispersa y era asistemática, exigiendo acudir a diversas fuentes no siempre coordinadas, y en algunos casos desactualizadas, fruto de numerosas modificaciones. Ahora bien, tras la aprobación del EBEP -y a excepción de las Comunidades Autónomas donde se ha efectuado un desarrollo integral-, la situación no ha mejorado, ya que al anterior sistema de fuentes se debe sumar otro texto más, y con él nuevas dificultades para el operador jurídico al intentar lograr su encaje en el sistema. A todo ello hay que añadir que en la situación económica actual todas las Administraciones Públicas están adoptando numerosas medidas vinculadas a materia presupuestaria, que tienen una importante repercusión en el marco jurídico regulador del empleo público.

La exposición de motivos del EBEP nos aventuraba un proceso de reforma "previsiblemente largo y complejo". No le faltaba razón.

\section{BIBLIOGRAFÍA}

AA.VV., Especial Sentencia 31/2010 del Tribunal Constitucional sobre el Estatuto de Autonomía de Cataluña de 2006, Revista Catalana de Derecho Público, EAPC-Generalidad de Cataluña, Barcelona, diciembre 2010.

80 Decreto 18/2009, de 27 de marzo, de la Consejería de Administraciones Públicas y Política Local, de procedimiento de selección y nombramiento de funcionarios interinos para desempeñar puestos de trabajo reservados a funcionarios de Administración Local con habilitación de carácter estatal.

81 De este modo, se regula parcialmente la creación y clasificación de puestos de trabajo reservados mediante Decreto 53/2010, de 5 de marzo, que regula el procedimiento para la constitución, modificación y disolución de Agrupaciones de Entidades Locales para sostenimiento en común de puestos de Secretaría e Intervención.

82 Decreto 350/2010, de 27 de julio, de la Consejería Gobernación y Justicia, que regula los méritos correspondientes al conocimiento de las especialidades de la organización territorial y de la normativa de la Comunidad Autónoma de Andalucía, de aplicación en los concursos de funcionarios con habilitación de carácter estatal.

83 Se regula el registro de funcionarios con habilitación de carácter estatal mediante Orden de 6 de marzo 2012 , de la Consejería de Administraciones Públicas, por la que se crea el fichero que contiene datos de carácter personal denominado "Fichero de funcionarios con habilitación de carácter estatal” de la Consejería de Administraciones Públicas.

84 De salir adelante el "borrador del Anteproyecto de Ley para la racionalización y sostenibilidad de la Administración Local" (versión 26.07.12) en los términos que está redactado, supondría, en esencia, retornar -aunque con importantes matices-, a la situación inmediatamente anterior a la aprobación del Estatuto Básico del Empleado Público; recuperando de este modo la Administración General del Estado, el catálogo de funciones que venía ejerciendo en relación a esta Escala de funcionarios.

85 Informe de la Comisión para el estudio y preparación del Estatuto Básico del Empleado Público. Instituto Nacional de Administración Pública. Madrid, 2005.

86 V., pp. 39 a 42. 
AA.VV., Estudio del Estatuto Básico del Empleado Público, Ayuntamiento de Madrid, Editorial Aranzadi, Navarra, 2008.

AA.VV., Documentos para la reforma de la función pública. Xunta de Galicia. La Coruña, 2008.

Álvarez Conde, Enrique, Reforma Constitucional y Reformas Estatutarias, Editorial lustel, Madrid, 2007.

Álvarez Rico, Manuel, González-Haba Guisado, Vicente $M^{\mathrm{a}}$ y Orduña Prada, Enrique, Administración y empleo público en España, CEMCI-Diputación Provincial de Granada, Granada, 2011.

Cantero Martínez, Josefa, “Las situaciones administrativas en el Estatuto Básico del Empleado Público”, Revista de Administración Pública, núm. 176, Madrid, mayo-agosto (2008), págs. 161-197.

Cantero Martínez, Josefa, “Estructura y ordenación del Empleo Público en las Administraciones de Castilla-La Mancha”, en Revista Jurídica de Castilla-La Mancha, Junta de Comunidades de Castilla-La Mancha, núm. 50, diciembre de 2011.

Cobo Olvera, Tomás y Vera Torrecilla, Rafael J. (Coor.), “Empleo público local. Prontuario para la selección organización y gestión del personal de Entidades Locales”, El Consultor de los Ayuntamientos (La Ley), Madrid, 2012.

De Sande Pérez-Bedmar, María, Empleo público local, Anuario de derecho municipal 2007, IDL-Universidad Autónoma de Madrid, Madrid, 2007, págs. 311-323.

Díez Quesada, Agustín y González-Haba Guisado, Vicente $M^{a}$, El Estatuto Básico del Empleado Público y sus posibilidades renovadoras del empleo público local, en Almonacid Lamelas, Víctor (Dir.), Estudios sobre la modernización de la Administración Local: teoría y práctica, El Consultor de los Ayuntamientos (La Ley), Madrid, 2009.

Martín Rebollo, Luis, El Estatuto Básico del Empleado Público: un Godot que no ha llegado, Revista de Administración Pública, núm. 174, Madrid, septiembre-diciembre 2007, págs. 129-159.

Ministerio de Presidencia, Boletín estadístico del personal al servicio de las Administraciones Públicas, Registro Central de Personal, Ministerio de la Presidencia, Madrid, julio 2011 (edición febrero de 2012).

Palomar Olmeda, Alberto (Coord.), El Estatuto Básico del Empleado Público y su incidencia en el ámbito local, CEMCI-Diputación Provincial de Granada, Granada, 2007.

Palomar Olmeda, Alberto, “Función pública: legislación, doctrina y jurisprudencia”, 4ª edición, Editorial Aranzadi, Navarra, 2012.

Redondo Ramírez, Rafael, Objeto y ámbito de aplicación. Clases de personal al servicio de las administraciones, en Romero Alonso, Lourdes y Gonzalo Muñoz, Javier (Coord.), El Estatuto Básico del Empleado Público: una aportación desde el mundo local, Diputación Provincial de Sevilla, 2010 (págs. 3-34).

Serrano Pascual, Antonio, El Estatuto Básico del Empleado Público y las Entidades Locales: valoración crítica, Revista Estudios QDL, Fundación Democracia y Gobierno Local, núm. 15, Barcelona, octubre de 2007.

Toña Güenaga, Fernando (Dir.) y otros, “Informe: Estatuto básico del empleado público y márgenes de configuración del legislador vasco para su desarrollo”, Instituto Vasco de Administración Pública, Oñate, Guipúzcoa, 2007. 